\title{
Factors of Investment Attractiveness of Mining Industries: Methodology Identification and Assessment
}

\author{
Gennady Alexandrov ${ }^{1}$, and Aleksandr Iablonev ${ }^{1, *}$ \\ ${ }^{1}$ Tver State Technical University, 170026, Af. Nikitin emb., 22, Tver, Russia
}

\begin{abstract}
In this study, we consider the highly relevant and, to a large extent, the debatable problem of the investment attractiveness of the subsoil use sphere and, above all, the investment attractiveness of mining enterprises. At the same time, attention is drawn to the fact that the development of mineral resources, unlike any other type of production activity, has its own specifics. It consists primarily in the fact that, along with such factors of production as capital and labor, which constitute the material basis of all production, the most important factor of production inherent in subsoil use is the subsoil itself. And it is their qualitative condition that determines to a large extent the results of the economic activity of mining enterprises. It is clear that without a comprehensive theoretical analysis of the role of the natural factor in the production process, as well as other objective and subjective factors, it is practically impossible to create a reliable theoretical basis for the development of practical measures, the implementation of which could significantly improve the investment attractiveness of extractive activities. Particular attention is paid to the methodology and methods for identifying and differentiating by specific signs specific barrier and restrictive factors that are considered in the investment process in the form of an unsystematic component of investment risk. It is shown that the results of a study of the nature of the influence of industry-specific factors on investment attractiveness are the basis for the development of specific measures to eliminate or minimize barriers to investment.
\end{abstract}

\section{Introduction}

The appeal to this problem is caused by a number of circumstances:

- firstly, the need to implement strategic national priorities formulated in a number of official federal documents. They defined the goals, directions and tasks of the State policy of the Russian Federation in the field of innovation and investment activities, contributing to the creation of favourable conditions for the concentration of investment resources and doing business in the Russian Federation. At the same time, the main tasks are considered: creating conditions for the development of competition and attracting investments in the economy of the Russian Federation and developing and implementing measures to improve

\footnotetext{
${ }^{*}$ Corresponding author: alvovich@mail.ru
} 
the conditions of entrepreneurial activity. The relevance of their decisions was highlighted in her speech on July 4, 2019 at the XXVIII International Financial Congress, the head of the Bank of Russia E. Nabiullina, pointing out the need for a "radical" improvement of the investment climate, considering it as the primary factor in economic policy aimed at economic growth and creating incentives for entrepreneurial initiative. "If one factor is really limiting - in our case it is primarily an investment climate," she notes, "no matter how we change other factors, we will not get an improvement in the situation" [1]. At the same time, the position of enterprises in the national economic system is largely determined by their ability: to successfully confront various kinds of external barrier and restrictive factors, threats and challenges, objectively inherent in the market economy itself, which, by definition, is spontaneous; and also eliminate all kinds of internal negative factors and trends in the activities of enterprises themselves;

- secondly, the needs of practice, since the calculation that the market, competition and personal interest will automatically provide business motivation for investment and innovation has not been justified. To a large extent this is due to the fact that the market environment is being formed too slowly and market mechanisms have been unable to perform regulatory and stimulating functions. As for the State, its economic policy is still not so effective in implementing measures of an organizational and legal nature and reforming organizational and economic relations aimed at creating an environment attractive for entrepreneurship and investment;

- thirdly, the need to create a methodologically sound concept for the formation of an attractive investment climate. Moreover, the issues of system analysis of the very concept of "investment attractiveness of an enterprise", as well as methods for identifying, differentiating, diagnosing and evaluating the factors, that make investment attractive, still remain highly debatable. It is clear, that the specifics of extractive activities cannot but affect their content and the special nature of their influence on the attractiveness of extractive enterprises.

Actually, this determines the purpose of this study, which is to formulate and theoretically substantiate approaches to identifying, differentiating, diagnosing and evaluating various kinds of factors and, ultimately, to assessing the level of investment attractiveness of investment objects. The emphasis is on the fact, that these factors are considered, first of all, as barriers and restrictions, challenges and threats, that are formed at each of the levels of the economic vertical (enterprise - industry - region - national economy) and, therefore, determine investment attractiveness of the enterprise itself, as the primary link in the hierarchical economic system.

\section{Materials and Methods}

Since, as noted above, the objects of our attention are mining enterprises that carry out a specific type of activity, the solution to the problem of increasing their investment attractiveness necessitates the use of a methodological approach "from the general to the particular and from it to the individual". That is, we consider the investment attractiveness of the enterprise from the position: firstly, of the general that is characteristic of this economic category, regardless of what industry the enterprise belongs to; secondly, that special that distinguishes the specifics of the industry (in this context, mining); and, accordingly, thirdly, of the separate one that distinguishes an enterprise engaged in a specific type of mining activity (for example, coal mining, oil production, peat mining, etc.). First of all, we note that investment attractiveness should be considered as an objective-subjective reality. That is, it is characterized not only by objective, but also by subjective component. 
The latter is due to the interests and preferences of the entrepreneur, as the subject of assessment, his attitude to the situation that he faces from the very beginning of the entrepreneurial choice and in which he has to carry out his activities, as well as understanding his own abilities to create and then develop his business. In other words, it is the position of the entrepreneur, as the subject of assessment, and his attitude to entry barriers and restrictions, challenges and threats in terms of how positively or, conversely, negatively affects the nature of investment attractiveness, is the basis for addressing issues of identification and assessment specific factors. It is important to take into account the fact that according to the logic of the entrepreneur making a decision on investing, he must evaluate investment risks, the level of which is directly predetermined by the same factors that determine the nature of investment attractiveness.

The consistent solution of the questions posed involves, firstly, the formation of typical groups of factors that mainly determine the attractiveness situation, and then, secondly, the identification and integration into the corresponding group of those specific factors that will be selected according to the principle of the greatest, in comparison with other factors, the impact on the formation of the investment climate and the assessment of its attractiveness.

Moreover, in the future, we will adhere to the logic that the investment attractiveness of an enterprise is determined, on the one hand, by the place of the enterprise in the system: enterprise - industry - region - national economy, and, on the other hand, by the presence and nature of the manifestation of specific factors, determining the investment climate at each of these levels of the hierarchical vertical. Thus, the process of identifying factors begins with the level of the enterprise as the initial link in the hierarchical system, and then the influence of each of the upper structural levels on the formation of the investment attractiveness of the enterprise itself as an investment object is determined.

The formation of the main groups of factors can be based on the position of economic theory that the production process is the unity of its two components: productive forces (means of labor and production conditions, such as organizational, social and environmental, as well as labor) and production relations. The latter, as you know, are implemented in certain organizational and economic forms (adequate to objective economic relations) and are regulated by administrative and legal institutions and mechanisms. The subject initial form of the economic system, in which the production process takes place, is the enterprise, the creation of which in a specific legal form, starting with investing, is the primary function of the entrepreneur. And since, as shown above, the essence of the production process is revealed in economic, administrative-legal, resource-technical, as well, as social and ecological aspects, it would be logical to form four characteristic groups, that determine investment attractiveness: economic, resource-technical, administrative-legal and socio-ecological factors, the diagnosis and assessment of which will assess the level of investment attractiveness, including an assessment of investment risks.

Having formed four groups of factors, one can determine those that could be integrated into the corresponding group by characteristic features. However, according to the "Pareto rule", not all available factors should be included in each of the four groups of factors to be diagnosed, but only $20 \%$ of those that, to the greatest extent, up to $80 \%$ [1], provide adequate estimates of investment attractiveness, and ultimately, the level of investment risks.

Assessing the factors of investment attractiveness, one cannot but dwell on such it components as threats and challenges for entrepreneurs, which are considered in publications, mainly, as factors of economic security of business [2]. It is clear that in making his choice, the entrepreneur must evaluate them as part of other factors that affect investment attractiveness and can cause damage to the enterprise. Their identification is also important from the point of view, that safety in normative acts is characterized as the 
absence of unacceptable risk, associated with the possibility of damage [3]. The benchmark here is determined by the fact that for an investor, risk is defined as an acceptable value.

Together with other factors, they can be considered as external and internal, objective and subjective. External threats are usually caused by objective factors, the negative effects of which arise independently of enterprises and entrepreneurs. They are genetically predetermined, firstly, by the spontaneous nature of a market economy and its inherent contradictions, secondly, by the activities of the State and other local authorities in implementing economic policies, and, thirdly, by the presence of counterparties, suppliers and consumers, partners at enterprises and, especially, competitors, as subjects of industry and inter-industry competition. The developed general methodological approaches and the principles of identifying, diagnosing and assessing barrier and restrictive factors, challenges and threats allow us to diagnose them from the standpoint of that specific (see, for example: [4]), that distinguishes enterprises engaged in specific activities, for example, in our case of mining.

\section{Results and Discussion}

So, with regard to enterprises engaged in extractive activities, the specifics of economic, administrative-legal, resource-technical and socio-environmental factors are due, first of all, to the fact that among the factors of production the most important in this area are mineral deposits. This explains, firstly, the special nature of the system of production relations that develop in the subsoil use regarding the production process, and, secondly, the emergence of a new component of this system - rental relations. All this predetermines the special nature of the formation and distribution of economic results from extractive activities, and ultimately, determines the presence of specific factors in each of the four species groups, that find out the investment attractiveness of extractive enterprises. Recall that the developed fields can vary significantly in quality, primarily natural characteristics. As a result, there are differences in the productivity and efficiency of enterprises and, most importantly, in the amount of profit.

Thus, enterprises operating in the best natural and climatic conditions initially have advantages, having greater productive power compared to those enterprises that operate in the worst natural environment deposits. Therefore, ceteris paribus, they make more profit. In other words, entrepreneurs, operating in fields of different natural quality, are initially in an unequal position. Here it would be important to note, that there is a common problem for the extractive industries for the distribution of the additional profit, received by enterprises operating in better conditions, that is, between them and the owner of the deposits.

Therefore, the lack of reliable economic methods that contribute to the resolution of these contradictions negatively affects the investment attractiveness of extractive activities. And since the specifics of extractive production is determined, first of all, by the presence of rental relations [5], a solution to this problem is possible only at the country hierarchical level. In other words, only at the federal level can an economic mechanism be created to coordinate and realize the interests of mining entities: the owner of mineral deposits (the State), on the one hand, and business entities (entrepreneurs), on the other. It is clear that the creation of such a mechanism and the development of specific measures in relation to extractive enterprises causes the need to distinguish in each of the four groups those factors that, along with the general factors inherent in enterprises of any other type of activity, determine the specifics of extractive industries.

As for the special factors of the economic group, it is primarily those that represent barriers and restrictions in creating a new or developing an existing mining enterprise. They are due to the fact that, firstly, there is a difficult access to mineral deposits, which are very limited and, moreover, are the object of monopoly property of the State. Secondly, as noted 
above, deposits significantly differ in natural quality, which affects economic results, which may not correspond to the expectations of the investor in terms of obtaining the mass and rate of return, the necessary volumes and payback periods of investments. And thirdly, as a result, rental relations arise, which imply payment for the use of fields taken for development, which is carried out in the first order, regardless of the profit received as a result, and if it is lacking, it is made at the expense of entrepreneurial income.

Thus, the organizational and economic mechanism for distributing profits on entrepreneurial income and rent, which is inadequate to the interests of entrepreneurs, is the most important barrier specific factor of the administrative-legal group. However, the question of what this mechanism should be remains exclusively controversial, which is noted by a number of economists (see, for example: $[6,7]$ ).

At the same time, attention is drawn to the fact that Russia has developed a specific mechanism for withdrawing rental income by administering taxes. Many researchers $[8,9]$, including us [5], justify the provision that taxes perform mainly a fiscal function. Moreover, the inadequate nature of tax administration can be considered as a destabilizing factor [10]. Therefore, it is proposed, including by us, a different approach that combines tax administration and rental regulation. It is due to the fact, that in subsurface use, as noted above, economic relations are formed relative to two objects: a deposit, as an object of paid use, and an enterprise, as a payer for use, for which payment by its nature is a cost that reduces the amount of gross profit. Thus, it would be possible to remove the contradiction between the subjects of subsoil use arising from the seizure of rents and taxes by establishing rental payments adequate to the natural quality of the deposit, and the taxation of entrepreneurial income from extractive activities.

As for the group of resource-technical factors, it is very specific in relation to extractive industries, since, along with other factors of this group, it contains natural, barrier factors of exclusively natural origin. At the same time, it is important not only that enterprises operate in fields that are qualitatively different from each other, but also that during their development during the "life cycle" of the field they are gradually depleted, production conditions deteriorate, which results in a decrease in business results. Therefore, overcoming or at least minimizing the negative impact of natural barrier factors on the investment attractiveness of mining activities objectively requires reforming the State economic policy that provides for the possibility of adjusting rents as the fields become depleted, and, no less important, setting rental terms within the deposit's "life cycle".

The last of the groups of factors that we are considering that form the investment climate are the factors that make up the socio-ecological group. In relation to other groups of factors, the socio-ecological group is becoming increasingly important, since it is associated with the quality of the living environment and people's livelihoods. This is primarily due to the fact, that in the process of making investment decisions more and more attention is given to corporate social and ecological responsibility (CSER), as the norm for doing business. Mining, as a special type of activity, is distinguished by the specifics of its socio-ecological characteristics that affect investment attractiveness. Nowadays, the development of the country's economy cannot be considered in isolation, firstly, from how efficiently natural resources are used and, secondly, what kind of mining activity has an environmental impact. And since we, like the whole modern world, are concerned about the state of the environment and the presence of a large complex of social problems related to ecology, the importance of socio-ecological factors in the formation of a favorable investment climate will only increase. Thus, this group of factors affects both investment attractiveness and investment risks, and, as a result, the decision to invest. 


\section{Conclusion}

The authors hope that the results of the study presented in the article will allow, firstly, to deepen and expand ideas about methodological approaches to determining specific factors, characterizing the investment attractiveness of mining enterprises; secondly, to focus on these factors, as the basis for the formation of a certain part of the unsystematic component of investment risk; thirdly, to identify areas in which it is necessary to develop specific measures to eliminate or minimize factors specific to the extractive industries, that negatively affect the investment attractiveness of investment objects and, accordingly, reduce the unsystematic (diversified) component of investment risks. Ultimately, the implementation of the measures developed should contribute to the activation of investment processes in the extractive industries.

\section{Acknowledgement}

The reported study was funded by RFBR, project number 20-010-00124: "Improving the concept of economic security and assessing the level of its security in the aspect of investment attractiveness of enterprises".

\section{References}

1. R. Koch, The 80/20 Principle: The secret of Achieving More with Less (Nicholas Brealey, Boston, 1997)

2. A. I. Tatarkin, A. A. Kuklin, Econ. Reg., 2:30, 25-39 (2012)

3. T. N. Gvozdkova, A. Lozhnikova, Yu. Suslova, S. Anyona, E3S Web Conf., 105, 04006 (2019)

4. S. Anwar, Econ. Model., 26:3, 626-630 (2009)

5. G. Alexandrov, A. Iablonev, E3S Web Conf., 41, 04024. 2018

6. Ch. P. Jones, Investments: Analysis and Management (John Wiley \& Sons Inc., New York, 2012)

7. M. P. Devereux, R. Griffith, H. Simpson, J. Public Econ., 9:3-4, 413-435 (2007)

8. D. Barbosa, V. M. Carvalho, P. J. Pereira, Econ. Model., 52:B, 742-748 (2016)

9. A.T. Tavares-Lehmann, A. Coelho, F. Lehmann, Prog. Int. Bus. Res., 7, 89-117 (2008)

10. V.Yu. Padalkin, G.N. Strukov, A.M. Prygunkov, L.I. Churikov, Proc. of the Voronezh State University of Engineering Technologies, 81:2, 383-386 (2019) 